\title{
Brazilian co-authorship overseas: \\ the Journal of Post Keynesian Economics and related journals*
}

\author{
Caio de Andrade Lopes ${ }^{\dagger}$ \\ Renata Borges Lopes ${ }^{\ddagger}$
}

\begin{abstract}
The purpose of this study is to evaluate the importance of post-Keynesian ideas in the international scientific production of Brazilian researchers. The methodology uses an econometric technique to analyze Brazilian participation in nine scientific journals over the course of twenty years, from 1997 to 2016. The probability of a manuscript being published in the Journal of Post Keynesian Economics (JPKE) in comparison to other journals is evaluated by means of a logit model, wherein the dependent variable takes the value of one when atleast one of the article's co-authors is Brazilian, and zero otherwise. The results show that the probability of Brazilian co-authorship is greater for articles in heterodox journals, especially for those in JPKE.
\end{abstract}

Keywords: post-Keynesianism, logit models, history of economic thought JEL Classification: B29, B23

\footnotetext{
"We gratefully acknowledge comments and suggestions from two anonymous referees. We also thank Felipe Almeida, Eduardo Angeli, and other participants at the ANPEC- SUL conference.

† Universidade Federal do Piaui. E-mail: caiomdealopes@gmail.com

*Universidade Federal do Piaui. E-mail: renatalaborges@gmail.com
} 


\section{Introduction}

Conceptualizing economic heterodoxy is not an easy task. The most common approach is to regard it as a counterpoint, either to orthodoxy or to the mainstream view. In the first case, a heterodox economist would not endorse the current orthodox school of thought, which is today represented by neoclassical economics. Orthodox economics is the most recent and dominant school of thought, and it is also a more temporal and general conceptualization of economics. In the second alternative, if the mainstream view incorporated the ideas of individuals from academic institutions, organizations, and journals, and especially from major postgraduate research institutions, a heterodox economics would be characterized by less prestige and influence [Dequech, 2007; Colander et al., 2004].

Regardless of the concept of heterodoxy that is adopted, the following question arises: can Brazilian heterodox economists be seen as highly productive researchers? Indeed, neoclassical theory is far from unanimously accepted at Brazilian universities, with the main critique being its lack of adherence to the real world. According to Bresser-Pereira [2012], the core of neoclassical theory is a compilation of hypothetical-deductive models that offer a closed and comprehensive view of a timeless economic system. Identifying and understanding currents of thought that are contrary to orthodox economics in a given institutional environment is important for the overall understanding of the related society.

In this sense, a statistical analysis of academic production can shed light on currents of economic thought in scientific production within a given country and can also help delimit the weight of theories that are opposed to orthodoxy. This is only possible because scientific journals are usually related to specific schools of thought-such as JPKE and its relation to post-Keynesianism-which has undoubtedly influenced Brazilian scientific production [Carvalho, 2008].

The goal of this study is to empirically evaluate Brazilian researchers' participation in journals that are strongly influenced by post-Keynesian thought compared to their participation in more orthodox journals. To this end, the nine journals most often cited by JPKE between 1997 and 2016 (including JPKE itself) were analyzed, and a logit model was estimated with the journal dummies as regressors. The dependent variable assumed a value of one when at least one co-author of an article was Brazilian, and it was zero otherwise. The results supported the hypothesis that the probability of Brazilian co-authorship in the selected sample would be greater for heterodox journals, especially for JPKE. 
The sample was selected based on the journals cited by JPKE. This choice was not mandatory, nor would it necessarily lead to sensitive results. Nonetheless, the approach is supported by the pluralistic character of Brazilian scientific research in economics, as described by Fernández and Suprinyak [2016], Almeida et al. [2018] and Dequech [2018]. Post-Keynesianism - which characterizes JPKE—acts as a counterpoint to orthodoxy and to other heterodox approaches. The relevance of post-Keynesianism not only in Brazil but also in the world is explained in the next section.

The remainder of the text is organized into 7 sections. The next section provides a brief history of how post-Keynesianism emerged and consolidated its position as an important paradigm in Brazil. The third section briefly presents JPKE's genesis and its editorial policy. The fourth section explains the descriptive analysis and relevant information about the data. In section 5, the empirical model is developed, and section 6 describes the results and interprets the estimation of the model. In section 7, we present some robustness checks of our results. Finally, the last section concludes this paper.

\section{Post-Keynesianism in Brazil}

Delimiting the sources of post-Keynesianism in current economic thought is not an easy task. The starting point for the emergence of post-Keynesianism was not merely an event: it was a range of factors, the contextual background for which was the dissatisfaction of some 1960s economists with the prevailing school of thought. In the following decade, the establishment of the Cambridge Journal of Economics in 1977 and, a year later, of the Journal of Post Keynesian Economics, represented real possibilities for the acceptance of post-Keynesianism as a dominant paradigm in economics [King, 2002, p. 132-6].

In Brazil, the gateway to post-Keynesian thought were the universities with strong heterodox inclinations. According to Paula and Ferrari Filho [2010], in the 1980s and 1990s, the Universidade Estadual de Campinas (UNICAMP, Brazil) moved towards broader heterodox views that were not purely Marxist and incorporated the ideas of Keynes and his followers. Luiz G. Beluzzo, Maria C. Tavares, and Mario Possas made particularly important contributions along these lines. The postgraduate program at UNICAMP's Institute of Economics was instrumental in educating a new generation of Brazilian heterodox economists, and currently, several UNICAMP professors continue to conduct research from a post-Keynesian perspective.

Paula and Ferrari Filho [2010] highlight another institution critical to the 
dissemination of post-Keynesianism: the Universidade Federal do Rio de Janeiro (UFRJ). Since the 1990s, this institution has been strongly influenced by postKeynesian thinkers such as Paul Davidson. In the early 1990s, the Money and Financial System Study Group was created at UFRJ, coordinated by Professor Fernando Cardim de Carvalho and with help from UFRJ professors and other universities, including the Universidade Federal do Rio Grande do Sul (UFRGS) and the Universidade Estadual do Rio de Janeiro (UERJ). The Study Group employed a theoretical perspective that emerged from the work of Keynes, in line with postKeynesian schools of thought.

Throughout the 1990s and 2000s, other academic institutions opened their doors to Keynesian researchers, and many became important centers of heterodox thought: the Universidade Federal de Minas Gerais, the Universidade Federal do Paraná, the Universidade Federal de Uberlândia, the Universidade Federal Fluminense, the Universidade Estadual de São Paulo, Universidade de Brasilia, the Fundação Getúlio Vargas, and the University Católica de São Paulo. In 1996, the Brazilian Society of Political Economy was created. Despite its Marxist origins, the Brazilian Society of Political Economy welcomed publications from heterodox schools of thought [Paula \& Ferrari Filho, 2010].

In 2008, the Associção Keynesiana Brasileira (AKB) was formed during a meeting at UNICAMP. Its purpose was to gather researchers and policymakers who shared Keynesian views on economics. In a joint effort by the Institute of Economics at UNICAMP and the Money and Financial System Study Group, AKB became an important forum in Brazil for academic discussions on important Keynesian issues and their applications [Paula \& Ferrari Filho, 2010].

In addition to the receptivity of Brazilian universities to post-Keynesian thought, the high bibliographic productivity of post-Keynesian authors in national and international journals also facilitated the dissemination of their ideas throughout the country [Carvalho, 2008]. In this context, one question remains: does the empirical evidence support that post-Keynesianism's higher participation within Brazilian academic circles translates into a high representativeness of Brazilian authors in the JPKE?

\section{The emergence of the JPKE}

Since this study focuses its analysis on JPKE, it is only fair to point out the main events in the history of the journal, which represents an important postKeynesian principles dissemination tool. Three thinkers were instrumental in the 
formation of JPKE: Sidney Weintraub, John Galbraith, and Paul Davidson. They were primarily responsible for making the JPKE viable through the University of Rutgers, where Davidson was a professor. With the post-Keynesian social network already sufficiently developed in the United States, the first edition of JPKE was published in the fall of 1978 [Lee, 2009, p. 88].

The first editorial featured a statement of purpose that, according to Davidson [2002], remained relevant 25 years later: JPKE was a journal receptive to innovative theoretical studies targeting contemporary economic issues, and it encouraged theoretical and empirical analyses that challenged the orthodox conformism prevailing in American magazines. JPKE committed itself to the principle that the cumulative development of economic theory is only possible when such a theory is continuously challenged in terms of its ability to explain the real world and when it provides a reliable guide to public policy.

By the end of the 1970s and early 1980s, JPKE and Rutgers University had provided a foundation for the institutional framework of post-Keynesianism, but other forms of support emerged as well. In addition to JEI (in the United States) and the CJE (in England), which are included in this study's empirical analysis, there was the North-American Review of Radical Political Economics and the British Thames Papers in Political Economy [King, 2002, p. 223-4]. Overall, by the end of the 1980s, the post-Keynesian paradigm had consolidated, and a well-defined institutional framework had clearly been established. However, the diffusion of ideas outside the United States and England was quite low. The development of the social network and post-Keynesian institutional support is described in detail in Dammski et al. [2017].

Although the revolution urged by Robinson (1971) did not ultimately materialize, post-Keynesianism survived during the 1990s and 2000s as a small but active current of economic thought. [King, 2002, p. 259-60]. Over time, it has mainly been the students-inspired by their post-Keynesian professors-who have disseminated these ideas throughout the world, to places such as Australia, Austria, Canada, France, Italy, and Brazil. This dissemination of post-Keynesian thought, along with the acceptance of English as the dominant scientific language, solidified JPKE's position as a key proponent of ideas in this area [Lee, 2009, p. 194].

\section{Data}

The data used in this study were collected from the Web of Science (WoS) platform, which enables comprehensive exploration of research citations. WoS 
supplies information about an unparalleled range of international academic studies associated with a core of rigorously selected journals. It provides exclusive, new information by meticulously capturing metadata and generating citation connections Clarivate Analytics [2019].

First, it is important to emphasize that the data analyzed in this study were only from scientific articles in the selected journals. The journal selection process took place in two stages. First, a long, recent period was chosen for the study: from 1997 to 2016. Second, we selected the journals that were most frequently cited by the Journal of Post Keynesian Economics during this period. Table 1 shows the most frequently cited journals and their frequencies. It is not surprising that the Journal of Post Keynesian Economics cited itself most frequently during this period.

The data sample was selected in this manner, enabling a mapping of the dialogue between important journals and JPKE. The fact that the journals have different scopes was integral to the study's methodology. Information on each journal's objectives and areas of interest was collected via the SCImago platform, which also provides scientific production indicators for each journal and country, making it a reliable and objective source of scientific content. The characteristics of each journal according to SCImago are included in Annex A.

Table 1. Number of JPKE citations by source between 1997 and 2016.

\begin{tabular}{l|c}
\hline \multicolumn{1}{c|}{ Journal } & Number of citations in JPKE articles \\
\hline Journal of Post Keynesian Economics & 633 \\
American Economic Review & 332 \\
Cambridge Journal of Economics & 225 \\
Economic Journal & 184 \\
Quarterly Journal of Economics & 135 \\
Journal of Economic Issues & 132 \\
Journal of Political Economy & 130 \\
Journal of Economic Perspectives & 128 \\
Econometrica & 105 \\
\hline
\end{tabular}

Source: Elaborated by the author from Web of Science data.

Once the study sample was delimited in terms of journal and time period, the descriptive analysis of the data could proceed. The final database for this study consists of bibliographic information on the Table 1 journals for the period from 1997 to 2016. Figure 1 shows the graph of the proportion of articles with at least one Brazilian co-author for each journal. The prominence of JPKE is evident, providing 
an indication of the results obtained in the econometric model.

As has already been mentioned, the selected sample represents significant diversity in terms of scope. We linked scientific journals to different schools of thought using the classification proposed by Lee (2008). We identified heterodox journals as follows: JPKE, CJE, and JEI. In turn, the orthodox journals were as follows: ECONOMETRICA, JPE, JEP, AER, QJE, and EJ.

Figure 1. The proportion of articles with at least one Brazilian co-author.

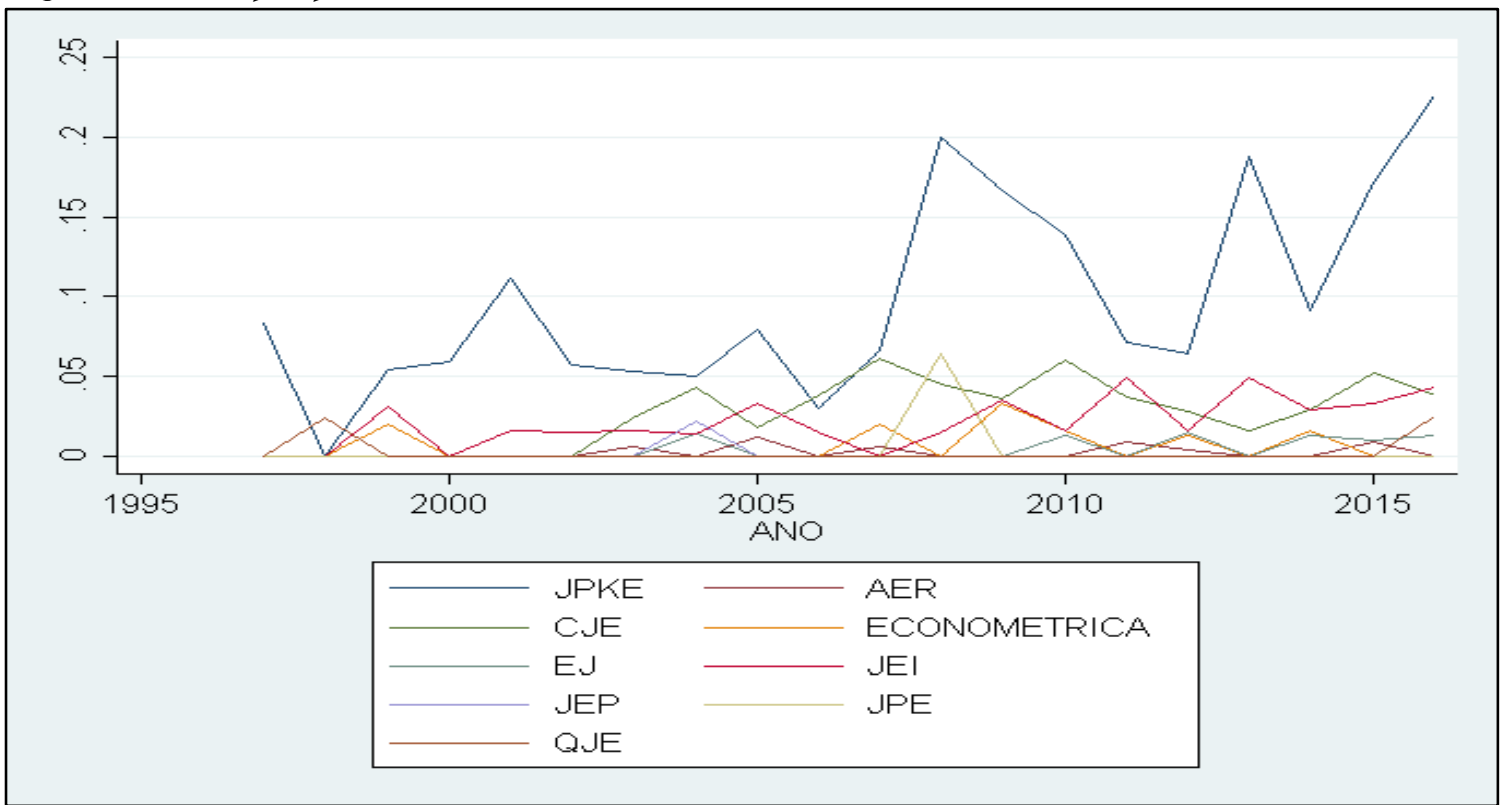

Source: Own authors' elaboration. Note: The variable consists of the sum of articles with at least one Brazilian co-author in a specific year and journal, divided by the total number of articles published by the journal in that year.

Table 2: Summary statistics.

\begin{tabular}{lcc}
\hline \multicolumn{1}{c}{ Variable } & Mean & (Std. Dev.) \\
\hline At least one Brazilian co-author & 0.013 & $(0.111)$ \\
AER & 0.315 & $(0.465)$ \\
CJE & 0.086 & $(0.281)$ \\
ECONOMETRICA & 0.099 & $(0.299)$ \\
EJ & 0.130 & $(0.336)$ \\
JEI & 0.108 & $(0.310)$ \\
JEP & 0.074 & $(0.262)$ \\
JPE & 0.064 & $(0.245)$ \\
JPKE & 0.056 & $(0.231)$ \\
QJE & 0.067 & $(0.250)$ \\
Co-authors & 1.891 & $(0.916)$ \\
\hline $\mathrm{N}$ & 12.122 & \\
\hline
\end{tabular}

Source: Own authors' elaboration. 
Table 2 presents the descriptive statistics of the main variables used in our analysis. Most of them are qualitative and represent features of the sample articles. More specifically, the table shows whether at least one co-author was Brazilian, the journal in which the article was published, the number of coauthors and the year of publication. Section 4 will give more details on the variables and econometric model.

\section{Methodology}

Binary response models, in which the dependent variable y assumes a value of 0 or 1 , have been widely discussed in the literature. In this methodology, the value of the variable $y$ is associated with the probability of its realization:

$$
y=\left\{\begin{array}{l}
1, \text { with probability } p \\
0, \text { with probability } 1-p
\end{array}\right.
$$

The regression model is given by the parameterization of the probability $p$ by means of the regressor $\mathrm{x}$ and a vector $\beta$ of dimension (Kx1). The conditional probability is given by the following:

$$
p_{i} \equiv P_{r}\left[y_{i}=1 \mid x\right]=F\left(x_{i}^{\prime} \beta\right)
$$

in which $F($.$) is a cumulative distribution function (cdf), which ensures that 0 \leq p \leq$ 1. The distribution of F must vary according to the model chosen such that the interpretation of the marginal effects of the regression depends on the cdf chosen. In turn, the marginal effect, EM, of a variation with a continuous regressor $j$ is represented by the following:

$$
E M=\frac{\partial P_{r}\left[y_{i}=1 \mid x\right]}{\partial x_{i j}}=F^{\prime}\left(x_{i}^{\prime} \beta\right) \beta_{j}
$$

in which $F^{\prime}(\bar{z})=\frac{\partial F(z)}{\partial z}$ corresponds to the probability distribution function (pdf). That is, the marginal effect is a function of the regressor itself and thus varies according to the evaluation value of $\mathrm{x}$. In the logit model, the marginal effect can be evaluated more easily. If the probability of the realization is $p_{i}=e^{x_{i}^{\prime} \beta} /\left(1+e^{x_{i}^{\prime} \beta}\right)$, the marginal effect in this case is $\partial p_{i} / \partial x_{i j}=p_{i}\left(1-p_{i}\right) \beta_{j}$. However, the functional aspect of the logit model makes the analysis of the marginal effect on the odds ratio more interesting, as we can see

$$
\frac{p_{i}}{1-p_{i}}=e^{x_{i}^{\prime} \beta}
$$




$$
\ln \left(\frac{p_{i}}{1-p_{i}}\right)=x_{i}^{\prime} \beta
$$

The odds ratio, $p_{i} /\left(1-p_{i}\right)$, calculates the probability of $y=1$ in relation to $y=0$. In the logit model, the logarithm of the odds ratio is linear for the regressors; thus, its interpretation is simpler. Finally, the econometric model used in this study is a logit given by the following regression

$y_{i}=\beta_{a e r} x_{i 1}+\beta_{c j e} x_{i 2}+\beta_{e j} x_{i 3}+\beta_{q j e} x_{i 4}+\beta_{j e p} x_{i 5}+\beta_{j e i} x_{i 6}+\beta_{j p e} x_{i 7}+\beta_{e c o} x_{i 8}+$

$\beta_{\text {ano }} T_{i}+\beta_{\text {aut }} w_{i}+\varepsilon_{i}$

in which the dependent variable $y_{i}$ takes a value of 1 when article $i$ has at least one Brazilian co-author and is 0 otherwise. The independent variables $x_{i j} \operatorname{com} j=$ $1,2, \ldots 8$ represent the journal dummies. If article $i$ is in journal $j$, then $x_{i j}$ takes a value of 1 ; otherwise, its value will be zero. It is worth noting that the variable referring to JPKE is omitted from the regression since it is our baseline variable. Thus, the interpretation of estimated parameters of other dummies must always be performed in relation to JPKE, which is evident in the results section. Finally, the variables $T_{i}$ and $w_{i}$ denote the year the article was published and the number of coauthors for article $i$, respectively.

The econometric model presented here obviously has a poor specification; that is, there are other unused variables related to $y_{i}$. However, given the purpose of this study, we only have to check if the correlation between the omitted variable and the variables for journals is sufficient to change the order of interpretation of the estimated parameters. This idea will be further explained in section 5 .

\section{Results}

The results of the logistic regression were very illuminating. First, Table 3 shows quite clearly that all coefficients are negative and significant at $1 \%$ in relation to the journal dummies. Therefore, the probability of finding a Brazilian co-author is greater for articles in the Journal of Post Keynesian Economics (the baseline variable) than for articles in the other journals in our sample. The trend variable $t$ is positive and significant at 1\%, indicating an increase in Brazilian participation in authorship over the years.

Table 3 shows the odds ratios. Regarding the journal dummies, changing from JPKE to any other journal was associated with a decrease in the probability of Brazilian co-authorship, since the coefficients were all smaller than one (as expected, 
given the negative sign in coefficients). For example, the probability of finding at least one Brazilian co-author in AER was 0.015 times smaller than in JPKE. After JPKE, the journals with the greatest probability of having a Brazilian co-author were CJE and JEI ${ }^{1}$.

Table 3. Logit regression: the probability of at least one Brazilian co-author

\begin{tabular}{l|ccc}
\hline \hline & Coefficients & (Std. Dev.) & Odds Ratio \\
\hline AER & $-4.198^{* * *}$ & $(0.369)$ & 0.015 \\
CJE & $-1.434^{* * *}$ & $(0.226)$ & 0.238 \\
ECONOMETRICA & $-3.193^{* * *}$ & $(0.407)$ & 0.041 \\
EJ & $-3.631^{* * *}$ & $(0.435)$ & 0.026 \\
JEI & $-1.631^{* * *}$ & $(0.234)$ & 0.195 \\
JEP & $-4.780^{* * *}$ & $(1.013)$ & 0.008 \\
JPE & $-3.923^{* * *}$ & $(0.723)$ & 0.019 \\
QJE & $-4.140^{* * *}$ & $(0.727)$ & 0.015 \\
Trend & $0.073^{* * *}$ & $(0.015)$ & 1.076 \\
Co-authors & $0.345^{* * *}$ & $(0.093)$ & 1.413 \\
Constant & $-150.155^{* * *}$ & $(31.754)$ & \\
\hline Pseudo R & & 0.202 & \\
\hline Source: Ownas. & & 12.122 & \\
\hline
\end{tabular}

Source: Own authors' elaboration. Note: JPKE corresponds to the omitted dummy. ${ }^{* * *}$ Significant at $1 \%$.

Thus, there was greater relative participation of Brazilian authors in three of the journals involved in the consolidation of the post-Keynesian institutional support structure than in other journals. This result suggests that post-Keynesian/heterodox thought has strongly influenced Brazilian researchers. To be more precise, the distance between international and Brazilian researchers seems to be smaller regarding heterodox approaches than it is in relation to orthodox economics. Following Fernández and Suprinyak [2016], economics in Brazil can aptly be described as pluralistic, with competing schools of thought enjoying relatively secure institutional positions. In part, these results can be attributed to the role played by ANPEC, the Brazilian economics association, in mediating conflicts among graduate

\footnotetext{
${ }^{1}$ The difference between CJE and JEI is not statistically significant.
} 
programs affiliated with different research traditions.

It should be clarified that this methodology allows us to evaluate how the probability of finding a Brazilian co-author changes when comparing articles from different journals. Caution should be used, however, when drawing associations between journals and orthodoxy/heterodoxy or particular schools of thought, even when a correlation between Brazilian authors and heterodox journals is evident.

\section{Robustness}

In this section, we conduct robustness exercises to evaluate the sensitivity of the results in relation to the sample. The first analysis concerns the sample period. We do not incorporate periods prior to 1997 because of the low international relevance of Brazilian researchers. According to data collected by Kocher and Sutter [2001], scientific production in economics was linked to 15 influential international journals, and authors with a Brazilian affiliation were responsible for only $0.03 \%$ of the world's academic production. ${ }^{2}$ The authors used data from only five years: 1977 , 1982, 1987, 1992, and 1997. Moreover, their sample had five journals in common with the sample of this paper: Economic Journal, Journal of Political Economy, American Economic Review, Quarterly Journal of Economics, and Econometrica. ${ }^{3}$

Table 4. Logit regression: the probability of at least one Brazilian co-author.

\begin{tabular}{c|l|ccc}
\hline \multicolumn{1}{l|}{} & Coefficients & (Std. Dev.) & Odds Ratio \\
\hline & AER & Omitted & Omitted & Omitted \\
& OJE & Omitted & Omitted & Omitted \\
& ECONOMETRICA & $-2.833^{* * *}$ & $(1.073)$ & 0.058 \\
& EJ & Omitted & Omitted & Omitted \\
& IEI & $-1.990^{* * *}$ & $(0.659)$ & 0.136 \\
IEP & Omitted & Omitted & Omitted \\
IPE & Omitted & Omitted & Omitted \\
& OJE & $-2.504^{* *}$ & $(1.090)$ & 0.081 \\
& Trend & 0.163 & $(0.181)$ & 1.076 \\
& Co-authors & -0.158 & $(0.480)$ & 1.413 \\
\hline
\end{tabular}

${ }^{2}$ This result was obtained by considering the number of authors, their affiliations, and the impact of each journal.

${ }^{3}$ It is worth mentioning that a journal's date of founding is a binding condition in the work of Kocher and Sutter [2001]. 
Table 4. Logit regression: probability of at least one Brazilian co-author (continuation)

\begin{tabular}{|c|c|c|c|c|}
\hline \multirow[t]{10}{*}{$2002-2006$} & AER & $-2.951^{* * *}$ & $(0.677)$ & 0.0522 \\
\hline & CJE & -0.812 & $(0.526)$ & 0.443 \\
\hline & ECONOMETRICA & Omitted & Omitted & Omitted \\
\hline & EJ & $-3.201^{* * *}$ & $(1.061)$ & 0.040 \\
\hline & JEI & $-1.108^{* *}$ & $(0.525)$ & 0.330 \\
\hline & JEP & $-2.599 * *$ & $(1.074)$ & 0.074 \\
\hline & JPE & Omitted & Omitted & Omitted \\
\hline & OJE & Omitted & Omitted & Omitted \\
\hline & Trend & 0.077 & $(0.140)$ & 1.080 \\
\hline & Co-authors & 0.234 & $(0.222)$ & 1.263 \\
\hline \multicolumn{5}{|r|}{ Obs. $[=2205]$} \\
\hline \multirow[t]{10}{*}{ 2007-2011 } & AER & $-4.134^{* * *}$ & $(0.634)$ & 0.016 \\
\hline & CJE & $-1.101^{* * *}$ & $(0.366)$ & 0.332 \\
\hline & ECONOMETRICA & $-2.473^{* * *}$ & $(0.561)$ & 0.084 \\
\hline & EJ & $-4.379^{* * *}$ & (1.036) & 0.012 \\
\hline & JEI & $-1.875^{* * *}$ & $(0.446)$ & 0.153 \\
\hline & JEP & Omitted & Omitted & Omitted \\
\hline & JPE & $-2.567^{* * *}$ & $(0.752)$ & 0.076 \\
\hline & OJE & Omitted & Omitted & Omitted \\
\hline & Trend & 0.032 & $(0.104)$ & 1.033 \\
\hline & Co-authors & $0.293^{*}$ & $(0.173)$ & 1.341 \\
\hline
\end{tabular}


Table 4. Logit regression: probability of at least one Brazilian co-author (continuation)

\begin{tabular}{l|l|ccc}
\hline $2012-2016$ & AER & $-4.757^{* * *}$ & $(0.654)$ & 0.008 \\
& CJE & $-1.735^{* * *}$ & $(0.374)$ & 0.176 \\
ECONOMETRICA & $-3.799^{* * *}$ & $(0.761)$ & 0.022 \\
EJ & $-3.271^{* * *}$ & $(0.566)$ & 0.037 \\
JEI & $-1.573^{* * *}$ & $(0.381)$ & 0.207 \\
JEP & Omitted & Omitted & Omitted \\
JPE & Omitted & Omitted & Omitted \\
& OJE & $-4.166^{* * *}$ & $(1.054)$ & 0.015 \\
& Trend & $0.170^{*}$ & $(0.099)$ & 1.186 \\
& Co-authors & $0.506^{* * *}$ & $(0.136)$ & 1.659 \\
\hline
\end{tabular}

Obs. [=2919]

Source: Own authors' elaboration. Note: Constants were not reported. ${ }^{* * *}$ Significant at $1 \%$, **Significant at $5 \%,{ }^{*}$ Significant at $1 \%$.

Therefore, as a robustness exercise, we will divide our sample into four equal periods and re-estimate the parameter vector. Table 4 presents the results for our logit model at five-year intervals. It is immediately apparent that the results do not vary considerably, although with the small sample size, numerous journal dummies have been omitted in some periods. This is due to the small international inclusion of Brazilian academic researchers because our dependent variable does not present enough variation for analysis in some journals across the subsamples. [Novaes, 2008; Faria et al., 2007a, 2007b]. However, the signs of the estimated parameters suggest that the results are robust, with a greater possibility of finding articles that have at least one Brazilian coauthor in Keynesian journals and specifically, in JPKE.

Another interesting exercise in robustness is to vary the dependent variable according to nationality. With this purpose, we identify the most frequent nationalities in the sample.

The set of selected countries and their logistic regression results are shown in Table 5. This exercise allows us to evaluate whether a result arises from the fact that some journals have greater variability in terms of author nationality. In other words, this exercise assesses whether the likelihood of finding an article with at least one co- 
author of a given nationality is always greater for JPKE. For the sake of simplicity, Table 5 shows only the coefficients of the logistic function, with the interpretation being based on the sign of the estimated parameter. Although Australia's result is the most similar to that of Brazil, the results suggest that no other nationality is as strongly associated with JPKE as Brazil.

Table 5. Logit regression: the probability of at least one co-author from country $J$.

\begin{tabular}{|c|c|c|c|c|c|c|}
\hline J-Country & Brazil & Australia & Canada & China & England & France \\
\hline$\overline{\mathrm{AER}}$ & $-4.198^{* * *}$ & $-1.742^{* * * *}$ & -0.265 & 0.132 & $-0.738^{* *}$ & $-0.935^{* * *}$ \\
\hline JE & $434^{* * *}$ & 0.169 & $-0.804^{* * *}$ & -0.000 & $1.102^{* * *}$ & 0.119 \\
\hline AETRICA & $-3.193^{* * *}$ & $-1.180^{* * * *}$ & -0.010 & 0.761 & -0.074 & 0.029 \\
\hline e & $-3.631^{* * *}$ & $-0.450^{*}$ & -0.317 & 0.516 & $1.109^{* * * *}$ & $-0.358^{*}$ \\
\hline EI & $-1.631^{* * *}$ & -0.337 & -0.290 & 0.086 & $-0.899 * * *$ & $-0.394^{*}$ \\
\hline EP & $-4.780^{* * *}$ & $-0.994^{* * *}$ & $-0.782^{* * *}$ & -1.242 & $-0.681^{* * *}$ & $-1.215^{* * *}$ \\
\hline $\mathrm{E}$ & $-3.923^{* * *}$ & $-1.646^{* * *}$ & 0.003 & 0.578 & $-0.524^{* * *}$ & $-0.597^{* *}$ \\
\hline dJE & $-4.140^{* * *}$ & $-1.907^{* * *}$ & $-0.631^{* *}$ & -0.883 & $-0.459^{* * *}$ & $-0.547^{* *}$ \\
\hline rend & $0.073^{* * *}$ & 0.0151 & $0.014^{*}$ & $0.058^{* * *}$ & 0.002 & $0.049^{* * *}$ \\
\hline Co-authors & $0.345^{* * *}$ & $0.246^{* * *}$ & $0.148^{* * *}$ & $0.438^{* * *}$ & $0.320^{* * *}$ & $0.340^{* * *}$ \\
\hline \multirow[t]{2}{*}{ Constant } & $-150.1^{* * *}$ & -33.7 & $-32.3^{* *}$ & $-122.6^{* * *}$ & -8.1 & $-102.3^{* * *}$ \\
\hline & Italy & Netherlands & Spain & Switzerland & USA & Germany \\
\hline$\overline{E R}$ & $-1.180^{* * *}$ & 0.197 & $-0.815^{* * *}$ & 0.406 & $2.337^{* * *}$ & 0.090 \\
\hline JE & $0.929^{* * *}$ & $1.345^{* * *}$ & $-1.074^{* * *}$ & 0.316 & $-1.072^{* * *}$ & $0.669^{* *}$ \\
\hline $\mathrm{CONC}$ & $-1.016^{* * *}$ & 0.470 & $-0.547^{* *}$ & $1.021^{* *}$ & $1.373^{* * *}$ & 0.109 \\
\hline J & -0.108 & $1.503^{* * *}$ & -0.124 & $1.121^{* *}$ & -0.081 & $1.049^{* * *}$ \\
\hline $\mathrm{EI}$ & $-0.786^{* * *}$ & $1.279^{* * *}$ & $-0.715^{* *}$ & -0.837 & $0.776^{* * *}$ & 0.211 \\
\hline EP & $-1.347^{* * *}$ & -0.364 & $-1.686^{* * *}$ & 0.282 & $2.617^{* * *}$ & -0.323 \\
\hline L & $-0.758^{* * *}$ & 0.099 & $-0.751^{* *}$ & 0.129 & $2.454^{* * *}$ & -0.228 \\
\hline DJE & $-0.807^{* * *}$ & -0.179 & $-0.970^{* * *}$ & 0.211 & $2.433^{* * *}$ & $-0.679^{*}$ \\
\hline Trenc & $0.061^{* * *}$ & 0.011 & $0.043^{* * *}$ & $0.061 * * *$ & $-0.011^{* * *}$ & $0.065^{* * *}$ \\
\hline Co-au & $0.308^{* * *}$ & $0.414 * * *$ & $0.428^{* * *}$ & $0.435^{* * *}$ & $-0.098^{* * *}$ & $0.339^{* * *}$ \\
\hline Constant & $-126.4^{* * *}$ & -28.1 & $-90.2^{* * *}$ & $-128.7^{* * *}$ & $22.5^{* * *}$ & $-134.7^{* * * *}$ \\
\hline
\end{tabular}

Source: Own authors' elaboration. Note: ${ }^{* * *}$ Significant at $1 \%,{ }^{* *}$ Significant at $5 \%$, ${ }^{*}$ Significant at $10 \%$ (Israel and Sweden failed to converge).

There are two more issues that should be taken into consideration. The first is related to a key question: why did we select the most cited journals in JPKE as opposed to the most cited journals in other journals? The answer can be found in our method. As already mentioned, we must consider variation in journal scope, since our aim is to correlate the author's nationality with the salient school of thought in a given country. If we survey another journal, such as ECONOMETRICA or AER, 
we find that JPKE, CJE, and JEI are not among the top ten most-cited journals. This result is expected, since heterodox economists often cite mainstream journals, even if just to criticize the dominant paradigm. On the other hand, the citation-related networks of JPKE, CJE, and JEI are similar; these journals cite orthodox and heterodox journals in a more balanced way [Kapeller, 2010].

Finally, we should explain why we chose JPKE and its eight most-cited journals as our sample. We could have chosen the seven or nine most-cited; however, we need to understand whether increasing or decreasing the sample size would help us answer our question. Incorporating additional journals into our sample may not change the result that the probability of finding a Brazilian co-author is greater in JPKE than in ECONOMETRICA, for example. Considering the possibility that the way we have constructed our sample is affecting our result - that is, that there has been an endogenous sample selection-is even more important. However, there is no reason to believe that the model suffers from selection bias. As a main result of our benchmark model, we can sort the journals according to the likelihood of Brazilian co-authorship in the study period: JPKE, CJE, JEI, ECONOMETRICA, EJ, JPE, OJE, AER, and JEP. When we remove the articles related to any of these journals, this order remains.

Let us say we decide to discard JEP from our analysis, as it is not a peerreviewed journal and cannot be compared to other journals, whose publications follow the standard competition process. We can do this, and it does not alter our main conclusions. This is not something we should be concerned about, since the aim of our research is to correlate coauthors' nationality with the sample's journals, which are associated with different schools of thought. Therefore, there is no pretension of analyzing the scientific article market, in which the researchers are the suppliers and the journals are the source of demand. That is, if JEP's editorial staff invites a researcher to produce an article, it is because they believe that the researcher can produce an article that falls within the scope of their journal.

On the other hand, our methodology relies on more than pure correlation because it allows for a ceteris paribus analysis to be performed. We observe how much the probability of finding at least one Brazilian co-author changes when we move from one journal to another controlling for the number of co-authors and the year of publication. 


\section{Concluding remarks}

This study applied the logit model to evaluate the correlation between Brazilian co-authorship and post-Keynesian scientific journals, in particular JPKE. The basic information used to conduct this study was as follows: binary variables for the participation of Brazilian co-authors and dummies related to economic journals and trends. The period of analysis comprised 20 years, from 1997-2016, and the selected journals were those most cited by JPKE during this study period.

The results revealed that JPKE had the greatest probability of Brazilian coauthorship, followed by CJE, which also tends toward post-Keynesianism. The third position was held by JEI, which has more of an institutionalist character. In sum, the results suggest that the participation of Brazilian researchers in international journals tends to be in studies that deviate from the economic mainstream. Undoubtedly, institutions with a strong heterodox view (such as UNICAMP and UFRJ) have affected the results obtained in the econometric model. Although we can explain this finding by pointing to the institutional network of Brazilian universities, there are additional factors-both historical and sociological — that cannot be ignored. These merit space in the field's research agenda.

\section{References}

Almeida, I. C. de S., Almeida, R. G. de, \& Carvalho, L. R. de. (2018). Academic rankings and pluralism: The case of Brazil and the new version of Qualis. EconomiA, 19(3), 293-313. https://doi.org/10.1016/j.econ.2018.03.003

Bresser-Pereira, L. (2012). For a heterodox mainstream economics: An academic manifesto. Journal of Post Keynesian Economics, 35(1), 3-20. https://doi.org/10.2753/PKE0160-3477350101

Carvalho, F. J. C. de. (2008). Keynes e o Brasil. Economia e Sociedade, 17(spe), 569574. https://doi.org/10.1590/s0104-06182008000400003

Clarivate Analytics (2019). Web of Science. Retrieved from https://clarivate.com/products/web-of-science

Colander, D., Holt, R. P. F., \& Rosser, J. B. (2004). The changing face of mainstream economics. Review of Political Economy, 16(4), 485-499. https://doi.org/10.1080/0953825042000256702 
Dammski, B. R., Cavalieri, M. A. R., \& Pinto, J. S. D. P. (2017). Mapeando o póskeynesianismo: Uma abordagem cientométrica. Estudos Economicos, 47(4), 741-772. https://doi.org/10.1590/0101-416147447bmj

Davidson, P. (2002). Restating the purpose of the JPKE after 25 years. Journal of Post Keynesian Economics, 25(1), 3-7. https://doi.org/10.1080/ 01603477.2002 .11051344

Dequech, D. (2007). Neoclassical, mainstream, orthodox, and heterodox economics. Journal of Post Keynesian Economics, 30(2), 279-302. https://doi.org/10.2753/PKE0160-3477300207

Dequech, D. (2018). Applying the Concept of Mainstream Economics outside the United States: General Remarks and the Case of Brazil as an Example of the Institutionalization of Pluralism. Journal of Economic Issues, 52(4), 904-924. https://doi.org/10.1080/00213624.2018.1518532

Faria, J. R., Araujo Jr., A. F. de, \& Shikida, C. D. (2007a). The citation pattern of Brazilian economists. Estudos Econômicos (São Paulo), 37(1), 151-166. https://doi.org/10.1590/s0101-41612007000100006

Faria, J. R., Araujo, A. F., \& Shikida, C. D. (2007b). The international research of academic economists in Brazil: 1999-2006. Economia Aplicada, 11(3), 387406. https://doi.org/10.1590/S1413-80502007000300004

Fernández, R. G., \& Suprinyak, C. E. (2016). Manufacturing Pluralism in Brazilian Economics: The role of ANPEC as institutional mediator and stabilizer. In Anais do XLIV Encontro Nacional de Economia ANPEC (pp. 1-19). Foz do Iguaçu: ANPEC. Retrieved from https://www.anpec.org.br/ encontro/2016/submissao/files_I/i1424f2f0260f894e0f0ade26c6e3de7b0.d ocx

Kapeller, J. (2010). Some critical notes on citation metrics and heterodox economics. Review of Radical Political Economics, 42(3), 330-337. https://doi.org/10.1177/0486613410377855

King, J. E. (2002). A history of post Keynesian economics since 1936. Cheltenham: Edward Elgar Publishing. 
Kocher, M. G., \& Sutter, M. (2001). The Institutional Concentration of Authors in Top Journals of Economics During the Last Two Decades. The Economic Journal, 111(472), 405-421. https://doi.org/10.1111/1468-0297.00637

Lee, F. (2009). A history of heterodox economics: challenging the mainstream in the twentieth century (1st ed.). London: Routledge.

Lee, F. S. (2008). Informational directory for heterodox economists: Graduate and undergraduate programs, journals, publishers and book series, associations, blogs, and institutes and other websites. Kansas City, Missouri: Department of Economics, University of Missouri-Kansas City. Retrieved from http://citeseerx.ist.psu.edu/viewdoc/download?doi= 10.1.1.694.7543\&rep=rep1\&type $=$ pdf

Novaes, W. (2008). A pesquisa em economia no Brasil: Uma avaliação empírica dos conflitos entre quantidade e qualidade. Revista Brasileira de Economia, 62(4), 467-495. https://doi.org/10.1590/S0034-71402008000400005

Paula, L. F., \& Ferrari Filho, F. (2010). The spread of Keynesianism in Brazil: The origins and experience of the Brazilian Keynesian Association. European Journal of Economics and Economic Policies: Intervention, 7(2), 248-255. https://doi.org/10.4337/ejeep.2010.02.04

Robinson, J. (1971). Economic heresies: some old-fashioned questions in economic theory (1st ed.). London: MacMillan. 


\section{Appendix A. Scope of journals}

\section{Cambridge Journal of Economics}

The Cambridge Journal of Economics-founded in 1977 in the traditions of Marx, Keynes, Kalecki, Joan Robinson, and Kaldor-provides a forum for theoretical, applied, policy, and methodological research into social and economic issues. Its focus includes the following: 1) the organization of social production and the distribution of its product; 2) the causes and consequences of gender, ethnic, class, and national inequities; 3) inflation and unemployment; 4) the changing forms and boundaries of markets and planning; 5) uneven development and world market instability; 6) globalization and international integration. ${ }^{4}$

\section{Economic Journal}

The Economic Journal is among the foremost of learned journals in economics and is invaluable to anyone with an active interest in economic issues. It is a key information source for professional economists in higher education, business, government services, and the financial sector, and it represents unbeatable value for those who want to keep abreast of current thinking in economics. ${ }^{5}$

\section{Journal of Economic Perspectives}

The Journal of Economic Perspectives (JEP) attempts to fill a gap between the general interest press and most other academic economics journals. It aims to publish articles to achieve several goals: to synthesize and integrate lessons learned from active lines of economic research; to provide economic analysis of public policy issues; to encourage cross-fertilization of ideas among different fields of thinking; to offer readers an accessible source for state-of-the-art economic thinking; to suggest directions for future research; to provide insights and readings for classroom use; and to address issues relating to the economics profession. ${ }^{6}$

\section{Journal of Political Economy}

One of the oldest and most prestigious journals in economics, since 1892 the Journal of Political Economy has presented significant research and scholarship in economic theory and practice. The journal aims to publish highly selective, widely

\footnotetext{
${ }^{4}$ Available at www.scimagojr.com/journalsearch.php?q=213668tip=sid. Accessed Feb. 2, 2019.

${ }^{5}$ Available at www.scimagoj.com/journalsearch.php?q=23011\&tip=sid. Accessed Feb. 2, 2019.

${ }^{6}$ Available at www.scimagojr.com/journalsearch.php?q=28980\&tip=sid. Accessed Feb. 2, 2019.
} 
cited articles of current relevance that will have a long-term impact on economics research. JPE's analytical, interpretive, and empirical studies in a number of areasincluding monetary theory, fiscal policy, labor economics, development, micro and macroeconomic theory, international trade and finance, industrial organization, and social economics - are essential reading for all economists wishing to keep up with substantive new research in the discipline. ${ }^{7}$

\section{Journal of Economic Issues}

The Journal of Economic Issues is an internationally respected journal of institutional and evolutionary economics, and it serves as the official journal of the Association for Evolutionary Economics (AFEE). JEI publishes articles that describe aspects of evolving economies, economic problems, economic policy, economic history, and methodology. The primary mission of JEI is to present articles that use and develop the core ideas of institutional economics in discussions of current economic problems and policy alternatives. JEI is the leading journal on the ongoing debate in institutional economic theory and a major forum for discussion of solutions to real economic problems. ${ }^{8}$

\section{American Economic Review}

The American Economic Review is a general-interest economics journal. The journal is published quarterly and contains articles on a broad range of topics. Established in 1911, the AER is among the nation's oldest and most respected scholarly journals in the economics profession. ${ }^{9}$

\section{Quarterly Journal of Economics}

The Quarterly Journal of Economics is the oldest professional journal of economics in the English language. Edited by Harvard University's Department of Economics, it covers all aspects of the field: from the journal's traditional emphasis on micro-theory to both empirical and theoretical macroeconomics. ${ }^{10}$

\section{Econometrica}

Econometrica publishes original articles in all branches of economics-

\footnotetext{
${ }^{7}$ Available at www.scimagojr.com/journalsearch.php?q=24404\&tip=sid. Accessed Feb. 2, 2019.

${ }^{8}$ Available at www.scimagojr.com/journalsearch.php?q=28952\&tip=sid. Accessed Feb. 2, 2019.

${ }^{9}$ Available at www.scimagojr.com/journalsearch.php?q=22697\&tip=sid. Accessed Feb. 2, 2019.

${ }^{10}$ Available at www.scimagojr.com/journalsearch.php?q=29431\&tip=sid. Accessed Feb. 2, 2019.
} 
theoretical and empirical, abstract and applied-providing wide-ranging coverage across the subject area. It promotes studies that aim to unify the theoreticalquantitative and the empirical-quantitative approach to economic problems and that are penetrated by constructive and rigorous thinking. It explores a unique range of topics each year, from the frontier of theoretical developments in many new and important areas, to research on current and applied economic problems, to methodologically innovative, theoretical, and applied studies in econometrics. ${ }^{11}$

\section{Journal of Post Keynesian Economics}

The Journal of Post Keynesian Economics is a scholarly journal of innovative theoretical and empirical work that sheds fresh light on contemporary economic problems. It is committed to the principle that cumulative development of economic theory is only possible when the theory is continuously subjected to scrutiny in terms of its ability to both explain the real world and provide a reliable guide to the public.

\footnotetext{
${ }^{11}$ Available at www.scimagojr.com/journalsearch.php?q=19482\&tip=sid\&clean=0. Accessed Feb. 2, 2019.
} 